\title{
A light-assisted in situ embedment of silver nanoparticles to prepare functionalized fabrics
}

This article was published in the following Dove Press journal: Nanotechnology, Science and Applications

\author{
Her Shuang Toh' \\ Roxanne Line Faure ${ }^{2}$ \\ Liyana Bte Mohd Amin' \\ Crystal Yu Fang Hay' \\ Saji George ${ }^{1,3}$
}

'Centre of Sustainable Nanotechnology, School of Chemical and Life Sciences, Nanyang Polytechnic, Singapore, Singapore; ${ }^{2}$ DUT Analyses Biologiques et Biochimiques, IUT Génie Biologique, Dijon, France; ${ }^{3}$ Department of Food Science and Agricultural Chemistry, Macdonald Campus, McGill University, Sainte-Anne-de-Bellevue, QC, Canada

Correspondence: Saji George Department of Food Science and Agricultural Chemistry, Macdonald Campus, McGill University, Room MS-1039, 2I, III Lakeshore, Sainte-Annede-Bellevue, QC H9X 3V9, Canada

$\mathrm{Tel}+\mathrm{I} 5 \mid 43987920$

Email saji.george@mcgill.ca

\begin{abstract}
This article presents a simple, one-step, in situ generation of silver nanoparticlefunctionalized fabrics with antibacterial properties, circumventing the conventional, multistep, time-consuming methods. Silver nanoparticle formation was studied with a library of capping agents (branched polyethylenimine [BPEI] of molecular weight $\left[\mathrm{M}_{\mathrm{w}}\right] 10,000$ and 25,000, polyvinylpyrrolidone, polyethylene glycol, polyvinylalcohol and citrate) mixed with silver nitrate. The mixture was then exposed to an assortment of light wavelengths (ultraviolet, infrared and simulated solar light) for studying the light-assisted synthesis of nanoparticles. The formation of nanoparticles corresponded with the reducing capabilities of the polymers wherein BPEI gave the best response. Notably, the irradiation wavelengths had little effect on the formation of the nanoparticle when the total irradiation energy was kept constant. The feasibility of utilizing this method for in situ nanoparticle synthesis on textile fabrics (towel [100\% cotton], gauze [100\% cotton], rayon, felt [ $100 \%$ polyester] and microfiber [ $15 \%$ nylon, $85 \%$ polyester]) was verified by exposing the fabrics soaked in an aqueous solution of $1 \%(\mathrm{w} / \mathrm{v}) \mathrm{AgNO}_{3}$ and $1 \%(\mathrm{w} / \mathrm{v}) \mathrm{BPEI}$ $\left(\mathrm{M}_{\mathrm{w}} 25,000\right)$ to light. The formation of nanoparticles on fabrics and their retention after washing was verified using scanning electron microscopy and quantified by inductively coupled plasma optical emission spectrometry. The functional property of the fabric as an antibacterial surface was successfully demonstrated using model bacteria such as Staphylococcus aureus, Enterococcus faecalis and Escherichia coli. The successful generation of silver nanoparticlefunctionalized textile fabrics without the use of caustic chemicals, solvents and excessive heating presents a major step towards realizing a scalable green chemistry for industrial generation of functionalized fabrics for a wide range of applications.
\end{abstract}

Keywords: BPEI, branched polyethylenimine, in situ synthesis, photoreduction, antibacterial fabrics, light-assisted nanoparticle synthesis

\section{Introduction}

The database of Project on Emerging Nanotechnologies reported a steady increase in consumer products containing nanoparticles (54 in 2005 compared to 1814 in 2014), and that silver is the most frequently used nanoparticle with its application in $24 \%$ of all the registered products. ${ }^{1,2}$ The antimicrobial property of silver nanoparticle is the primary reason for its wide-scale usage, including application in antibacterial fabrics, cosmetics, water filters and medicinal and food packaging products. ${ }^{1-4}$ Consequently, the annual production of silver nanoparticle has been estimated as 320 tonnes and is likely to increase in the coming years. ${ }^{5}$ Given the wide range of applications, there is vested interest in developing scalable, cost-effective and "greener" methods for generating nanoparticles-embedded substrates/matrices. ${ }^{6}$ 
Common methods for silver nanoparticle synthesis include chemical reduction and laser light-assisted synthesis. One of the chemical reduction techniques is the Lee-Meisel method (modified from classic Turkevich) wherein a reducing agent (e.g. sodium borohydrate) is added to convert silver ions to metallic nanoparticles. ${ }^{7.8}$ However, the above method often has residual side products. To circumvent the possible contamination from side products, light-assisted top-down synthesis can be employed. Studies have shown that light, in the form of laser, ablates the silver plate in a sodium dodecyl sulfate or polyvinylpyrrolidone (PVP) solution to obtain nanoparticles. ${ }^{9}{ }^{10}$ Microwave-assisted synthesis has also been attempted to yield monodisperse nanoparticles. ${ }^{11}$ Often, the nanoparticles thus synthesized are used for their embedment onto substrates at a later stage.

One of the conventional methods for embedding nanoparticles onto fabrics is to draft the nanoparticles via the three-step method of pad-dry-cure. ${ }^{12,13}$ For instance, to embed silver particles on polyester, the fabric is soaked in the nanoparticle suspension for $20 \mathrm{~s}$, followed by drying and curing at a high temperature of $190{ }^{\circ} \mathrm{C} .{ }^{12}$ Ideally, the substrate should be able to withstand the high temperature used in the curing process. Alternately, some methods increase nanoparticle retention through chemical modifications of the matrix and/or nanoparticles. ${ }^{14}$ This lengthy pad-dry-cure process can create substantial chemical wastage resulting in increased production cost. Hence, there is a shift towards in situ synthesis on the substrate to simplify the process and promote more economical and environmental-friendly solutions.

In situ synthesis usually involves immobilizing the metal ions onto the substrate before a chemical reduction reagent is employed to convert the ions into nanoparticles. For example, poly(acrylamide)-based polymers can be applied on cotton as a linker to promote affinity for metal ions before chemically reducing the metal ions into nanoparticles in situ with borohydride. ${ }^{15,16}$ Earlier works have shown that silk fibers grafted with alternating layers of polymers with complimentary charges can trap silver nanoparticles made by light-assisted synthesis. ${ }^{17}$ Another technique employed is the gyration which relies on injection of solution with simultaneous centrifugal spinning to obtain polymeric nanofibers. ${ }^{4,18-22}$ Antibacterial nanoparticles could also be introduced into the polymeric solution before the synthesis process of gyration to obtain antimicrobial polymer fibers. ${ }^{4}$ Conductive wearable fabrics can be synthesized with a one-step chemical vapor deposition of poly(3,4-ethylenedioxythiophene) polymer film. ${ }^{6}$ While these methods may work under controlled experimental conditions, scale-up and cost effectiveness of these methods for industrial application are questionable due to the involvement of multiple reagents, expensive process, washing processes and generation of waste products.

In this work, we address the possibility of generating silver nanoparticle-functionalized textile fabrics using a lightassisted single-step process as an alternative to conventional process. The objective was to optimize a greener and scalable process for the in situ generation of silver nanoparticle that results in no/minimal waste and substantially lowered energy footprint. We tested different capping agents mixed with silver nitrate and wavelengths of lights for optimizing a process for light-assisted synthesis of silver nanoparticle. While the wavelength of light had little effect on the nanoparticle synthesis, results showed that the reducing capability of the polymer correlated with its ability to generate nanoparticle and branched polyethylenimine (BPEI) of molecular weight $\left(\mathrm{M}_{\mathrm{w}}\right)$ 25,000 (BPEI 25K) produced the best result. We then investigated the in situ embedment of silver nanoparticle when textile fabrics soaked in a solution of BPEI and silver nitrate were exposed to light. The functionalized fabrics inhibited the growth of Escherichia coli, Staphylococcus aureus and Enterococcus faecalis. The successful generation of silver nanoparticle-functionalized fabrics without the use of caustic chemicals, solvents and excessive heating presents a major step towards realizing a scalable green chemistry for industrial applications.

\section{Materials and methods Chemicals}

Silver nitrate ( $\geq 99.8 \%)$, nitric acid (69\%), tryptic soy broth (TSB) and absolute ethanol were obtained from Merck (Kenilworth, NJ, USA). BPEI (99\%, $\mathrm{M}_{\mathrm{w}}$ 10,000 [BPEI 10K]) was supplied by Alfa Aesar (Haverhill, MA, USA). BPEI 25K (<99\%), PVP (purum, $\mathrm{M}_{\mathrm{w}} \sim 40,000$ ) and gold(III) chloride ( $\geq 99.99 \%$ ) were bought from Sigma Aldrich (St Louis, MO, USA). Polyethylene glycol (PEG; pharmaceutical grade, $\mathrm{M}_{\mathrm{w}}$ 1500) was obtained from Sinopharm Chemical Reagent Co. Ltd (Shanghai, People's Republic of China). Polyvinylalcohol (PVA; 99.0-99.8\%) was supplied by JT Baker (St Phillipsburg, NJ, USA). Citrate (citric acid trisodium salt dehydrate, $\geq 99.0 \%$ ) was bought from MP Biomedicals (Santa Ana, CA, USA). S. aureus ATCC ${ }^{\circledR}$ 6538P, E. faecalis $\mathrm{ATCC}^{\circledR} 29212$ and E. coli ATCC $^{\circledR} 25922$ were obtained from Thermo Fisher Scientific (Waltham, MA, USA). Potassium permanganate (min 99\%) was obtained from Univar (Downers Grove, IL, USA). The woven fabrics, rayon $\left(12.68 \mathrm{mg} / \mathrm{cm}^{2}\right)$, gauze $(100 \%$ cotton, $\left.14.15 \mathrm{mg} / \mathrm{cm}^{2}\right)$, towel ( $100 \%$ cotton, $\left.19.63 \mathrm{mg} / \mathrm{cm}^{2}\right)$, microfiber (15\% nylon, $85 \%$ polyester, $\left.23.00 \mathrm{mg} / \mathrm{cm}^{2}\right)$ and felt $(100 \%$ 
polyester, $19.87 \mathrm{mg} / \mathrm{cm}^{2}$ ), were obtained from a local handicraft store. Commercially available washing detergent (powder; Lion Corporation, Tokyo, Japan) obtained from a local supermarket was dissolved in water at a concentration of $2 \%(\mathrm{w} / \mathrm{v})$. All chemicals and fabrics were used as received. Ultrapure water (deionized) from Millipore with a resistivity not less than 18.2 $\mathrm{M} \Omega \cdot \mathrm{cm}$ at $25^{\circ} \mathrm{C}$ was used to prepare all solutions.

\section{Light-assisted silver nanoparticle synthesis with different capping agents}

Aqueous solution of silver nitrate $(1 \%, \mathrm{w} / \mathrm{v})$ was added to solutions of capping agents (polyethylenimine/PVP/PEG/ citrate/PVA) prepared in deionized water at a final concentration of $1 \%(\mathrm{w} / \mathrm{v})$. Twofold serial dilutions were performed on the $1 \%(\mathrm{w} / \mathrm{v})$ solution with deionized water to prepare concentrations ranging from $0.5 \%(\mathrm{w} / \mathrm{v})$ to $0.125 \%(\mathrm{w} / \mathrm{v})$. These solutions were vortexed for $2 \mathrm{~min}$ and subjected to water bath sonication for $30 \mathrm{~min}$ to ensure a well-mixed solution. The prepared solutions were kept in the dark before exposure to light. For this experiment with different capping agents, the solutions were exposed to light for $1 \mathrm{~h}$ under simulated solar light. The following section provides more information on the light source.

\section{Effect of light wavelength on the generation of silver nanoparticles}

Three different irradiation sources with different wavelengths were tested for their effect on the formation of silver nanoparticles. The infrared light source from Philip InfraPhil lamp emitted light with emission maxima of $1000 \mathrm{~nm}$ at 150-W power. The UV lamp with an emission wavelength of 10-400 $\mathrm{nm}$ was used as a source of UV light ( $30 \mathrm{~W}$; NuAire, Plymouth, MN, USA). Simulated solar light produced by a xenon lamp (with atmospheric correction factor) was used for imitating the solar spectrum (XES Series Class AAA solar simulator, XES-1600SE-200S; IVT Solar, Singapore, Singapore).${ }^{23}$ More information on the xenon lamp is given in Figure S1. The irradiation time was adjusted to 400, 2000 and $60 \mathrm{~s}$ for infrared light, UV light and simulated solar light, respectively, to obtain a radiance of $60 \mathrm{~kJ}$ across the different wavelengths. Figure S2 summarizes all of these characteristics of the various light sources. The nanoparticles produced were characterized for their size, shape, hydrodynamic diameter and surface charge.

\section{Physicochemical characterization of nanoparticles}

The silver nanoparticle suspension was diluted by a factor of 500 , and $10 \mu \mathrm{L}$ was drop-cast on a glass slide. After drying overnight in an oven, it was sputter-coated with platinum at $30 \mathrm{~mA}$ for $30 \mathrm{~s}$ using an auto fine coater (JFC-1600; JEOL USA Inc, Peabody, MA, USA). The nanoparticles were imaged using a scanning electron microscope (JSM-6701F; JEOL USA Inc). ImageJ software (National Institutes of Health, Bethesda, MD, USA) was used to determine the size of the nanoparticles from the scanning electron microscopy (SEM) images.

The UV-vis spectrum of the silver nanoparticle suspension was recorded by using a plate reader (SpectraMaxi3; Molecular Devices, Sunnyvale, CA, USA). For this, the silver nanoparticle suspensions were diluted by a factor of 10 , and $100 \mu \mathrm{L}$ was pipetted into each well of a clear 96-well plate. The absorbance was recorded for wavelengths ranging from 300 to $700 \mathrm{~nm}$ for assessing silver nanoparticles' signature UV-vis absorbance peak. ${ }^{24}$

The silver nanoparticle suspension obtained after exposure to light was used for the determination of the hydrodynamic diameter and zeta potential. They were measured using the technique of dynamic light scattering (Nano-ZS, Zetasizer Nano Series; Malvern Instruments, Malvern, UK), as detailed elsewhere. ${ }^{25}$

\section{In situ synthesis of silver nanoparticles on fabric and their characterization}

The precursor solution containing $1 \%(\mathrm{w} / \mathrm{v})$ silver nitrate and $1 \%(\mathrm{w} / \mathrm{v}) \mathrm{BPEI} 25 \mathrm{~K}$ was prepared as detailed in the "Lightassisted silver nanoparticle synthesis with different capping agents" section. It was serially diluted to obtain decreasing concentrations of $0.5 \%(\mathrm{w} / \mathrm{v}), 0.25 \%(\mathrm{w} / \mathrm{v}), 0.125 \%(\mathrm{w} / \mathrm{v})$, $0.06 \%(\mathrm{w} / \mathrm{v})$ and $0.03 \%(\mathrm{w} / \mathrm{v})$. Aliquots of $10 \mu \mathrm{L}$ from each solution were spotted onto the fabrics (rayon, cotton gauze, cotton towel, microfiber and felt) in rows of three. The last row contained $10 \mu \mathrm{L}$ of silver nitrate $(1 \%, \mathrm{w} / \mathrm{v})$ without any polymer. These fabrics were then irradiated under the simulated solar light for $1 \mathrm{~min}$. Subsequently, the fabrics were rinsed in water twice (to remove excess silver nitrate and unreacted polymer) and were dried in the dark.

The dried fabric samples were adhered on the sample holder firmly using double-sided carbon tape and were sputter-coated with platinum at $30 \mathrm{~mA}$ for $30 \mathrm{~s}$ using the auto fine coater. These specimens were imaged using SEM.

\section{Retention rate of silver nanoparticles after washing the fabrics}

The retention rate of the silver nanoparticles on the dried fabrics was investigated after subjecting the nanoparticlefunctionalized fabrics to a standardized washing protocol 
(BS1006:1990). Two sets of five fabric samples (rayon, cotton gauze, cotton towel, microfiber and felt in triplicates) modified with silver nanoparticles (previous section) were assigned as "before washing" and "after washing". The set of fabrics allocated as "before washing" was quantified using inductively coupled plasma optical emission spectrometry (ICP-OES) for their silver content and imaged with SEM. The fabrics under the "after washing" set were subjected to washing with $40 \mathrm{~mL}$ of detergent solution $(2 \%, \mathrm{w} / \mathrm{v})$ at $50 \pm 2{ }^{\circ} \mathrm{C}$ for $45 \mathrm{~min}$. The fabrics were then rinsed twice in water, ran under a running tap of distilled water to wash off the detergent and dried in an oven before silver quantification and imaging.

The two sets of fabrics were weighed and placed in individual Teflon flasks for acid digestion. Concentrated nitric acid $(9 \mathrm{~mL})$ was added to each of the Teflon flasks and heated under a gentle reflux at $180^{\circ} \mathrm{C}$ for more than $6 \mathrm{~h}$ to digest the fabric samples. The resulting solution was diluted with deionized water (final concentration of nitric acid was $5 \%[\mathrm{w} / \mathrm{v}]$ ) and filtered (0.2- $\mu \mathrm{m}$ filter; B. Braun, Melsungen, Germany). These solutions were used for silver quantification using an inductively coupled plasma optical emission spectrometer (Optima 2100DV; PerkinElmer, Waltham, MA, USA). A standard curve was generated using known concentrations of silver standards from 0.2 to $0.6 \mathrm{ppm}$, and it was used for calculating the amount of silver nanoparticles retained on the fabrics. Unmodified fabrics were also prepared similarly for determining the baseline silver content.

\section{Antibacterial studies on the nanoparticle- modified fabrics}

The fabrics (gauze and rayon) were cut into a size of $1 \mathrm{~cm}^{2}$ $(1 \mathrm{~cm} \times 1 \mathrm{~cm})$ and autoclaved in a bottle. After sterilization, these fabrics were dipped into the precursor solution containing silver nitrate $(1 \%, \mathrm{w} / \mathrm{v})$ and BPEI $(1 \%, \mathrm{w} / \mathrm{v})$ and exposed to simulated solar light for $1 \mathrm{~min}$. These fabrics were rinsed and dried overnight in the oven in a dark environment. The $1-\mathrm{cm}^{2}$ fabrics were used for all antibacterial experiments. Targeted antibacterial studies (bactericidal and bacteriostatic) were conducted in accordance with JIS L 1902 with slight modification.

For the bactericidal activity, single colony of $S$. aureus, E. faecalis and E. coli was separately inoculated into $50 \mathrm{~mL}$ of TSB ( $30 \mathrm{~g} / \mathrm{L})$ and cultured overnight. The optical density (OD) of bacterial suspension in the growth medium was measured using an OD meter (WPA Biowave CO8000 Cell Density Meter; Biochrom Ltd, Cambridge, UK), and the OD was adjusted to 1 by diluting the bacterial suspension with fresh TSB medium. Fabrics functionalized with silver nanoparticles (made with $1 \%[\mathrm{w} / \mathrm{v}]$ silver nitrate and $1 \%$ [w/v] BPEI $25 \mathrm{~K}$ precursor solution) were separately soaked in different bacterial cultures for $1 \mathrm{~h}$, individually transferred into clean tubes and incubated for an additional $1 \mathrm{~h}$. One milliliter of fresh TSB was added into each tube and sonicated in a water bath for $1 \mathrm{~min}$ to dislodge the bacteria on the fabric. The resulting solution was diluted by a factor of 10,000 , and $10 \mu \mathrm{L}$ of the diluted bacterial suspension was dropped onto one end of the square agar plate using a multichannel pipette and allowed to flow down vertically to the other end of the plate by keeping the plate in a slanted position. These plates were incubated at $37^{\circ} \mathrm{C}$ for $16 \mathrm{~h}$ before counting bacterial colonies in the respective lanes. The experiment was performed in triplicates to ensure reproducibility.

The bacteriostatic activities of the textile fabrics were also measured by monitoring the OD of bacterial suspension exposed to different fabrics containing silver nanoparticles. $S$. aureus, E. faecalis and E. coli were cultured overnight, and their OD was adjusted to 0.1 . Two milliliters of bacterial suspension was transferred into a cuvette, and a piece of dried fabric modified with silver nanoparticles was placed at the bottom of the cuvette. The cuvettes were placed in a shaking incubator (SSI3; Shel Lab, Cornelius, OR, USA) at $37^{\circ} \mathrm{C}$ at $150 \mathrm{rpm}$, and the bacterial growth was monitored hourly from 0 to $5 \mathrm{~h}$ and checked again after $24 \mathrm{~h}$. Bacterial growth kinetics was monitored with fabrics loaded with incremental levels of silver nanoparticles.

\section{Electron microscopy imaging of the fabrics exposed to bacteria}

Electron microscopy was conducted on the nanoparticlefunctionalized fabrics exposed to the bacterial cultures. The fabric samples exposed to bacteria for $1 \mathrm{~h}$ were submerged in $20 \mathrm{~mL}$ of water in individual tubes and were sequentially subjected to increasing levels of ethanol (20-90\%) to remove water. At the end of $24 \mathrm{~h}$, the moisture contents of the fabrics were reduced via their immersion in absolute ethanol. The fabric samples were gently placed on paper towel to absorb excess ethanol and attached to a sample holder using carbon tape. Then, the samples were imaged with an environmental scanning electron microscope (SU1510; Hitachi Ltd, Tokyo, Japan).

\section{Results and discussion}

Here, we report a light-assisted method for the in situ formation of silver nanoparticles on textile fabrics which is quicker, cleaner and cost effective in comparison to the traditional 
approaches. Initially, we screened a library of functionalizing agents and different wavelengths of light for the formation of silver nanoparticles from silver nitrate. While the wavelength of light had little effect, the reducing power of polymer was a determining factor for nanoparticle formation. Accordingly, the optimal result was obtained when silver nitrate mixed with BPEI-25K was exposed to solar simulated light. Subsequently, we successfully investigated the utility of this method for in situ synthesis of nanoparticle on the fibrils of textile fabrics. The antibacterial effect of the functionalized textiles was demonstrated using three strains of bacteria (S. aureus, E. faecalis and E. coli).

\section{Silver nanoparticle synthesis corresponded with the reducing capabilities of polymers}

Capping agents were individually mixed with silver nitrate before subjecting to irradiation under a simulated solar light for an hour. Comparing the six capping agents tested, from the UV-vis spectra in Figure 1A, BPEI 25K had the strongest absorbance at $420 \mathrm{~nm}$, a signature signal characteristic of silver nanoparticles. ${ }^{23,24}$ BPEI $10 \mathrm{~K}$ also showed a signal at 420 $\mathrm{nm}$, while the rest of the capping agents failed to show any significant absorbance suggesting the absence of nanoparticle formation. Since reducing agents are known to mediate the reduction of silver ions to nanoparticles, we hypothesized that the differential effect of polymers is dependent on their reducing capabilities.

To compare the reducing capabilities, the capping agents were added to $100 \mathrm{ppm}$ of potassium permanganate, which has a characteristic absorbance at 500 and $540 \mathrm{~nm}$. In the

A

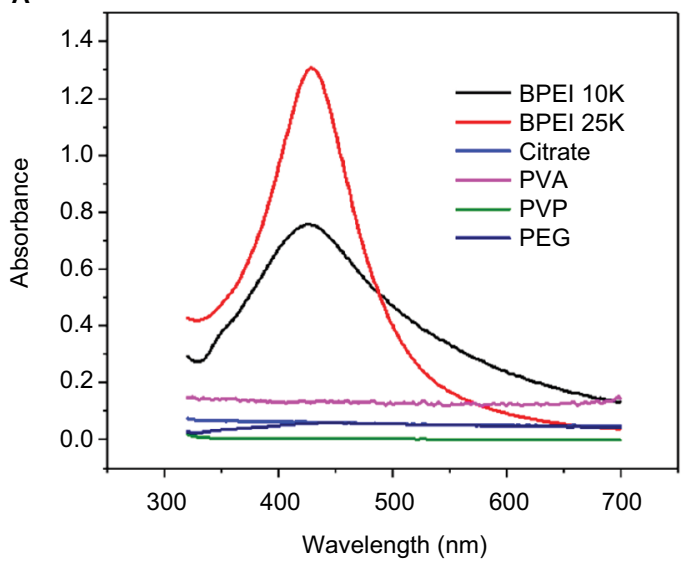

absence of capping agent, as observed in Figure 1B, 100 ppm of potassium permanganate had an absorbance of 0.53 at $540 \mathrm{~nm}$. As the purple solution decolorized, its absorbance at $540 \mathrm{~nm}$ decreased, correlating to the strength of the reducing capability of the capping agent. As BPEI was introduced to potassium permanganate, the solution decolorized quickly, indicating that the redox reaction occurred within a few seconds. From Figure 1B, it is evident that only BPEI $10 \mathrm{~K}$ and BPEI $25 \mathrm{~K}$ decreased the absorbance of potassium permanganate in a dose-dependent manner, suggesting their reducing capabilities. By comparing the results from Figure $1 \mathrm{~A}$ and $\mathrm{B}$, it is evident that the reducing capability of polymer is crucial for the formation of nanoparticles. Thus, it is also concluded that in the capping agent library, only BPEI is capable of synthesizing nanoparticles under the experimental conditions.

Based on the current observations and previous reports, Scheme 1 depicts a plausible route through which the redox reaction might occur. ${ }^{26}$ The photosensitization reaction depends on BPEI which acts as a sensitizer to reduce the silver ions to metallic silver. ${ }^{27}$ In turn, the different amine functionalities on BPEI are oxidized into various groups like aldehyde, nitro group and carboxylic acid. After that, BPEI (which also functions as capping agent) stabilizes the newly reduced metallic silver that cluster to form nanoparticles. With regard to other capping agents, none of them had the capability to interact with the oxidizing agent potassium permanganate. It is also interesting to note that citrate is known as a mild reducing agent in the classic Lee-Meisel method of nanoparticle synthesis under heating. ${ }^{7}$ However, it was unable to carry out the reduction of potassium permanganate and silver ions under the test conditions, explaining the absence

B

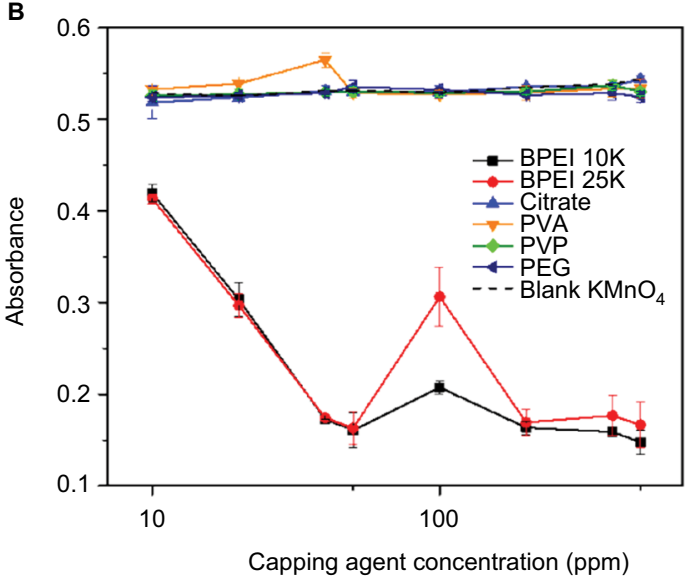

Figure I (A) The resulting UV-vis absorbance of the solutions (I\% [w/v] silver nitrate and equal weight of various capping agents) after I h of irradiation under simulated solar light. (B) Absorbance of 100-ppm potassium permanganate at $540 \mathrm{~nm}$ after addition of increasing concentrations of capping agents.

Abbreviations: BPEI IOK, branched polyethylenimine of molecular weight 10,000; BPEI 25K, branched polyethylenimine of molecular weight 25,000; PVA, polyvinylalcohol; PVP, polyvinylpyrrolidone; PEG, polyethylene glycol. 


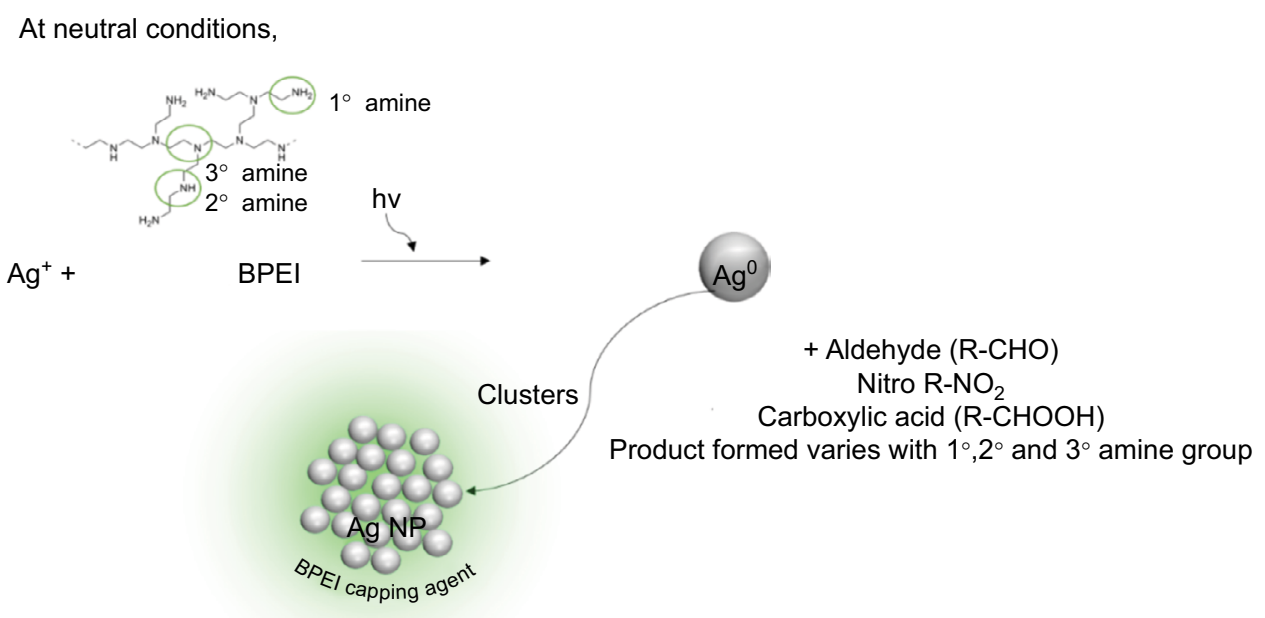

Scheme I Possible pathway taken by BPEI to reduce silver ion to give silver nanoparticles. Abbreviations: BPEI, branched polyethylenimine; NP, nanoparticle.

of nanoparticle formation (Figure 1A). In Figure 1B, there is a slight increase in potassium permanganate absorbance for $50-100 \mathrm{ppm}$ of BPEI. This is due to the precipitation of manganese(IV) oxide, and it is addressed in Figure S3.

After screening the library of capping agents and determining that BPEI is optimal for nanoparticle synthesis, a series of wavelengths were tested to determine their influence on the nanoparticle synthesis process. The wavelengths of infrared light, simulated solar light and UV light were tested. With BPEI $25 \mathrm{~K}$ as a capping agent, the precursor solutions were prepared as reported earlier. All the samples changed from colorless to brownish yellow after irradiation. The signature surface plasmon resonance signal of silver nanoparticle around $420 \mathrm{~nm}$ was observed for all samples as shown in Figure S2B. Nanoparticles generated through these different wavelengths also had similar hydrodynamic diameters between 60 and $80 \mathrm{~nm}$. This observation suggested that silver nanoparticles synthesis was indifferent to the wavelengths of light used when the total energy was kept constant. It should be noted that the time taken for generation of silver nanoparticles could vary depending on the irradiation energy. Accordingly, simulated solar light, with the highest irradiation energy among the light sources tested in this study, gave the fastest response in comparison to other wavelengths.

In addition, to demonstrate the possibility of synthesizing nanoparticles by natural sunlight, the silver nitrate solution (together with BPEI $25 \mathrm{~K}$ at $1 \%[\mathrm{w} / \mathrm{v}]$ ) was exposed to sunlight for increasing duration $(0.5,1,2,5$ and $10 \mathrm{~min})$. The UV-vis spectra of the resulting solutions suggested the formation of silver nanoparticle (Figure S4). Notably, most of the silver nanoparticles were formed within a short time (30 s), and the time increment did not bring significant increase in the absorbance at $420 \mathrm{~nm}$. This matches the observation in Figure 1B where the potassium permanganate was quickly reduced by BPEI, further supporting that this photosensitization reaction occurs quickly.

After identifying the optimal conditions of using simulated solar light as the light source and BPEI as the capping agent, the silver nanoparticles made with BPEI 10K and BPEI $25 \mathrm{~K}$ were subjected to further characterization to discern the possible differences brought by the influence of different $\mathrm{M}_{\mathrm{w}}$ of the polymer. The sizes and zeta potentials of nanoparticles formed with BPEI 10K and BPEI 25K (measured through dynamic light scattering and SEM) are summarized in Figure 2. As expected, silver nanoparticles functionalized with BPEI 10K and BPEI $25 \mathrm{~K}$ showed a positive zeta potential of around $+40 \mathrm{mV}$ (Figure 2C). Similarly, nanoparticles capped with these polymers were found to be spherical (Figure 2A and B), and they followed a logarithm normal distribution, with no signs of aggregation (i.e. lack of multiple peaks for size distribution). Despite the same chemical identity of BPEI, the silver nanoparticles produced differed in size. BPEI $25 \mathrm{~K}$ gave smaller particles of around $60-\mathrm{nm}$ diameter, while BPEI 10K-capped silver particles were 100 $\mathrm{nm}$ in size. This is also supplemented by Figure 1A where the broader UV-vis signal of BPEI 10K silver nanoparticles indicated their larger size compared to BPEI $25 \mathrm{~K} .{ }^{28}$ One of the possible reasons behind the size difference is the working mechanism of the capping agent. BPEI works via the electrosteric effect to prevent agglomeration and maintain the miniscule size of nanoparticles. ${ }^{29}$ The electrostatic effect is determined by the charge density, and the steric effect is dependent on the polymer size. Major differences in the chain 

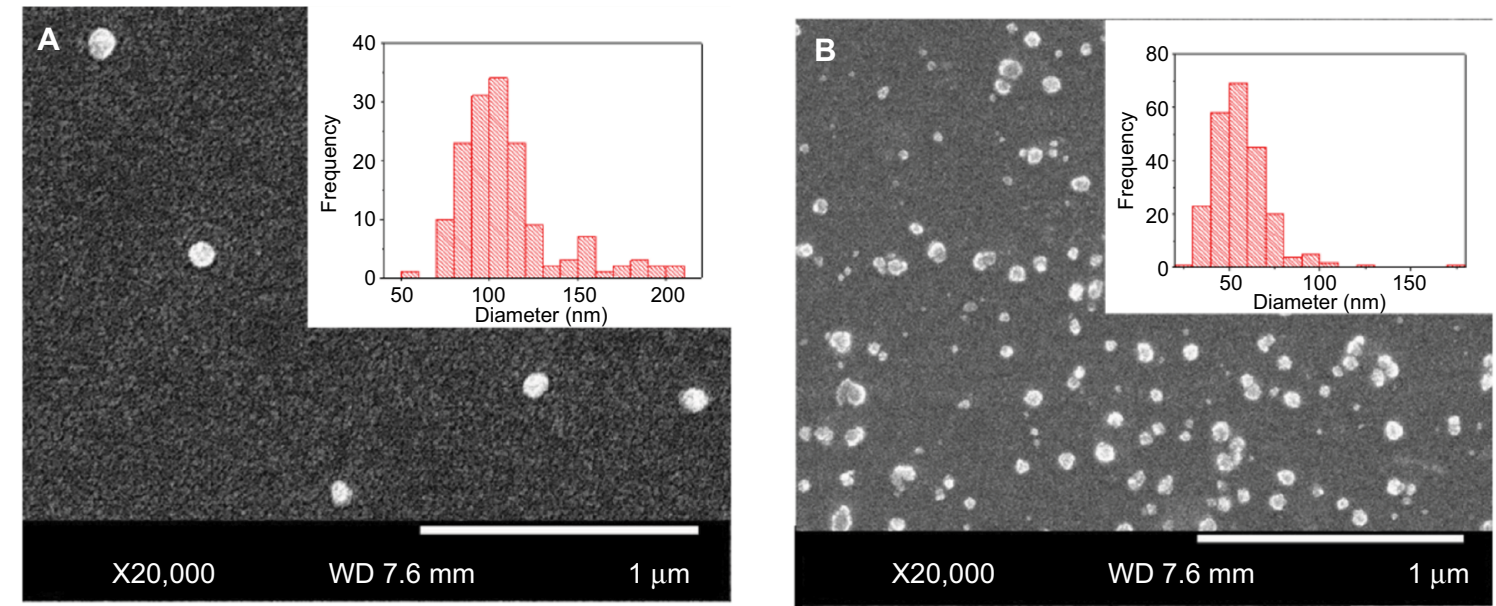

C

BPEI 10K-capped Ag NP

BPEI 25K-capped Ag NP

Hydrodynamic diameter

$95.9 \pm 0.7 \mathrm{~nm}$

$62.5 \pm 0.4 \mathrm{~nm}$

Diameter from SEM images

$109.5 \pm 27.44 \mathrm{~nm}$

$57.1 \pm 16.3 \mathrm{~nm}$

Zeta potential

$40.5 \pm 0.8 \mathrm{mV}$

$41.4 \pm 0.7 \mathrm{~nm}$

Figure 2 Characterisation of $\mathrm{Ag}$ nanoparticles using $\mathrm{I} \%(\mathrm{w} / \mathrm{v}) \mathrm{AgNO}_{3}$ and $\mathrm{I} \%$ (w/v) capping agent with I min of simulated solar light irradiation. SEM image of (A) BPEI IOK Ag nanoparticles and (B) BPEI $25 \mathrm{~K} \mathrm{Ag}$ nanoparticles. Inserts: size distribution of the particles. (C) Comparison between the two silver nanoparticles samples.

Abbreviations: SEM, scanning elecron microscopy; BPEI IOK, branched polyethylenimine of molecular weight 10,000; BPEI 25K, branched polyethylenimine of molecular weight 25,000; NP, nanoparticle.

length of BPEI and the density of the cationic entities can lead to varying degree of electrosteric effects to stabilize the individual nanoparticles..$^{30}$ Accordingly, BPEI 10K would have a weaker stabilizing effect in comparison to BPEI $25 \mathrm{~K}$, which may be the reason for the formation of relatively large-sized particles. Since the nanoparticles synthesized with BPEI $25 \mathrm{~K}$ were smaller and previous studies had reported a sizedependent antibacterial properties of silver nanoparticles, the rest of the experiments were carried out with BPEI $25 \mathrm{~K}$ as the capping agent. ${ }^{25}$ The positive surface charge of BPEI also confers additional antibacterial effect on the particles. ${ }^{31}$

\section{Successful in situ synthesis of silver nanoparticles on fabrics}

We tested the possibility of functionalizing textile fabrics of rayon, cotton gauze and cotton towel, given their usage in garments, wound dressing materials, bath towels, etc, which are the materials currently functionalized with silver nanoparticles. In addition, microfiber and felt were also used, given their relevance in making textile materials for cleaning surfaces and furniture coverings.

Applying the optimized method on the fabrics (as detailed in the "In situ synthesis of silver nanoparticles on fabric and their characterization" section) yielded a brownish yellow coloration on them (Figures 3A and S4) suggesting the formation of silver nanoparticles on these fabrics. With decreasing silver nitrate concentration, a color gradient was observed (Figure S5), suggesting that the amount of silver nanoparticles synthesized corresponded with the concentration of silver nitrate and polymer used. When these regions (on cotton gauze and rayon) were imaged using SEM, silver nanoparticles of spherical shape were seen adhered to the textile fibrils (Figure 3B and C). Notably, the nanoparticles were evenly dispersed across the fibers of the cotton gauze. Similar trends were also observed for the other three fabrics (i.e. felt, microfiber, cotton towel), and their SEM images are depicted in Figure S6.

To test the durability of silver nanoparticles binding onto the fabrics, the fabrics were washed by following the British standard of BS1006:1990. The silver contents were measured using ICP-OES before and after the washing. The amount of silver nanoparticles on the fabric is expressed as the percentage of the total amount of silver nitrate added to the fabric samples for nanoparticle synthesis. The images of fabric samples embedded with silver nanoparticles used in this study are shown in Figure S5. The silver content on the 

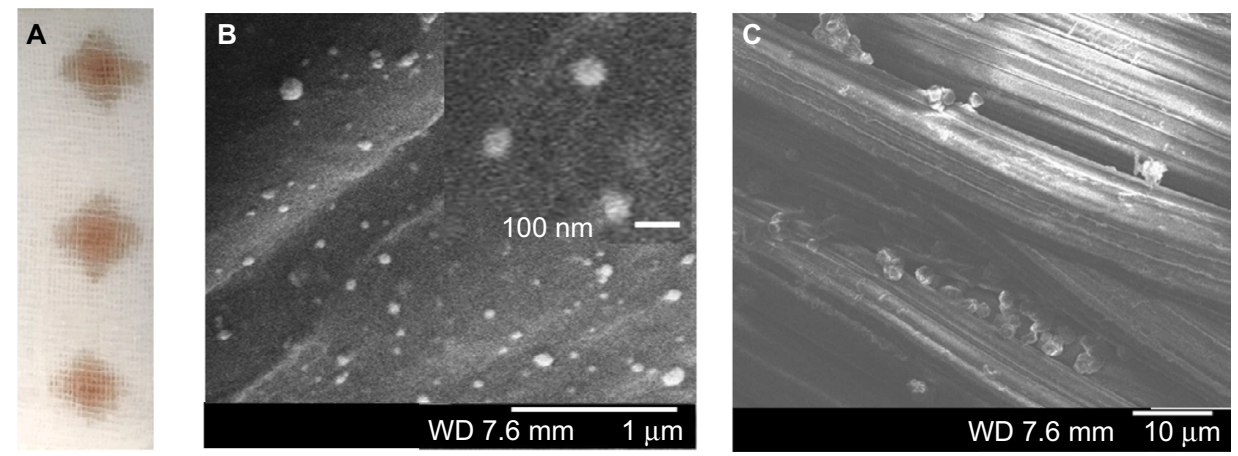

Figure 3 Ten microliters of the solution of $\mathrm{I} \%(\mathrm{w} / \mathrm{v}) \mathrm{AgNO}_{3}$ and $\mathrm{I} \%(\mathrm{w} / \mathrm{v}) \mathrm{BPEl} 25 \mathrm{~K}$ was added to cotton gauze and irradiated under simulated solar light for I min to give BPEI 25K silver nanoparticle-modified cotton gauze. (A) Appearance of BPEI 25K silver nanoparticle-modified cotton gauze. (B) SEM image of BPEI 25K silver nanoparticlemodified cotton gauze. Insert: magnified view of nanoparticles on the gauze. (C) SEM image of BPEl 25K silver nanoparticle-modified rayon fabric.

Abbreviations: BPEI 25K, branched polyethylenimine of molecular weight 25,000; SEM, scanning elecron microscopy.

fabrics before and after washing is summarized in Figure 4A. The nanoparticles on fabrics such as towel, gauze and rayon showed higher retention in comparison to those formed on felt and microfiber. The high retention of silver nanoparticles on rayon is further evidenced by the lack of discoloration of the fabric after washing (Figure 4B and C).

Washing with detergent hardly removed any silver nanoparticles embedded onto rayon and cotton towel (less than $10 \%$ ). Cotton gauze was capable of retaining $80 \%$ of its silver nanoparticles after washing. Perhaps, the presence of hydroxyl group on the cellulose-based fabrics (cotton gauze, cotton towel and rayon) helped to retain the nanoparticles. The electrostatic attraction between the amine and the hydroxyl groups may strengthen the connections between the nanoparticle and the fabric fibrils contributing to the higher retention of nanoparticles on these samples. On the other hand, felt and microfiber were unable to retain the formed nanoparticles. Felt, after a simple rinse, had only $20 \%$ of the original amount of silver left. Similarly, the microfiber fabric lost around half of its silver nanoparticles after the washing cycle. The waterresistant properties of felt (100\% polyester) and microfiber ( $15 \%$ nylon, $85 \%$ polyester) may have impeded the attachment of silver nanoparticles made in the aqueous solution of BPEI and silver nitrate, resulting in a greater loss of silver content. In addition, based on the silver content on the fabric (before washing) and the total amount of silver nitrate used (Figure 4), we can estimate the conversion rate of silver ions to silver nanoparticles to be greater than $90 \%$.

We verified the possibility of extending the optimized light-assisted silver nanoparticle synthesis to other metals as well by successfully synthesizing gold nanoparticles from BPEI and gold(III) chloride (Figure S7). In the absence of BPEI, the gold chloride solution remained yellow, indicating the importance of BPEI's dual functionality as reducing agent and capping agent for the generation of nanoparticles.
Nonetheless, the results from our studies showed successful in situ synthesis of nanoparticles (of silver and possibly other metals) on the different fabrics. We envisage that this simple method of generating nanoparticle-functionalized fabrics can be integrated as an additional step in the conveyer belt process of fabric dyeing. Possible design for integration of this method with the industrial process of fabric dyeing is depicted in Figure S8.

\section{Antibacterial activity of silver nanoparticle-embedded fabric}

Silver nanoparticles are well known for their antibacterial properties. ${ }^{2,32-34}$ Silver nanoparticles are able to bind to the sulfhydryl group present on proteins or cell membrane, and they are capable of releasing silver ions over a prolonged period. ${ }^{3,35}$ With the binding of silver to protein or enzymes, the latter could be inactivated resulting in detrimental effects on the bacteria. ${ }^{35}$ To test the efficiency of the silver nanoparticle-embedded fabrics for their antibacterial function, the fabrics were exposed to three different species of bacteria (S. aureus, E. faecalis and E. coli). These bacteria were chosen as they represent common pathogens and include both Gram-positive (S. aureus and E. faecalis) and Gram-negative strains (E. coli). Figure $5 \mathrm{~A}$ and B shows the growth of the three different bacteria after exposure to the nanoparticle-embedded fabric. In the absence of silver, all three species (from left to right: S. aureus, E. faecalis and E. coli) grew into numerous colonies. Almost no colonies of bacteria were detected on the plates with functionalized fabrics. The number of colonies in each row was counted and is tabulated in Figure 5C. The silver nanoparticles successfully inhibited the growth of all three strains of bacteria regardless of the fabric they were embedded on.

We also studied the growth kinetics of bacteria in the presence of functionalized fabrics. Figure $6 \mathrm{~A}-\mathrm{C}$ shows the 

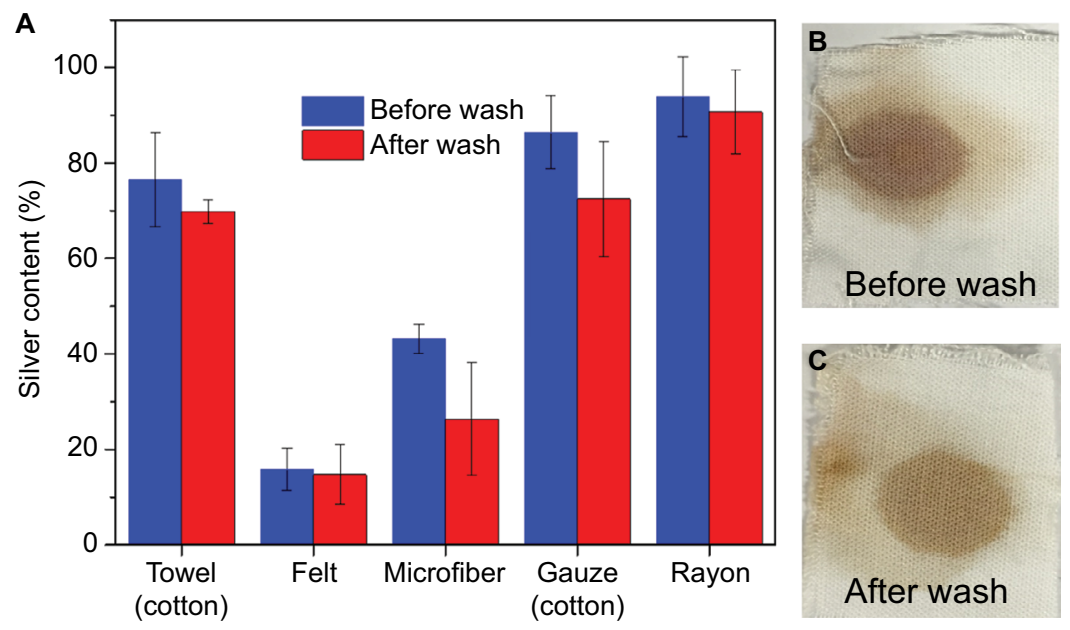

Figure 4 (A) The amount of silver on each fabric before and after washing as a percentage of the amount of silver nitrate added. (B) Before washing: BPEI 25K silver nanoparticles-modified rayon made from a precursor solution containing $1 \%$ (w/v) silver nitrate and equal weight of BPEI $25 \mathrm{~K}$ with a I-min simulated solar light irradiation. (C) After washing with soap solution (BSI006:1990).

Abbreviation: BPEI 25K, branched polyethylenimine of molecular weight 25,000.

A

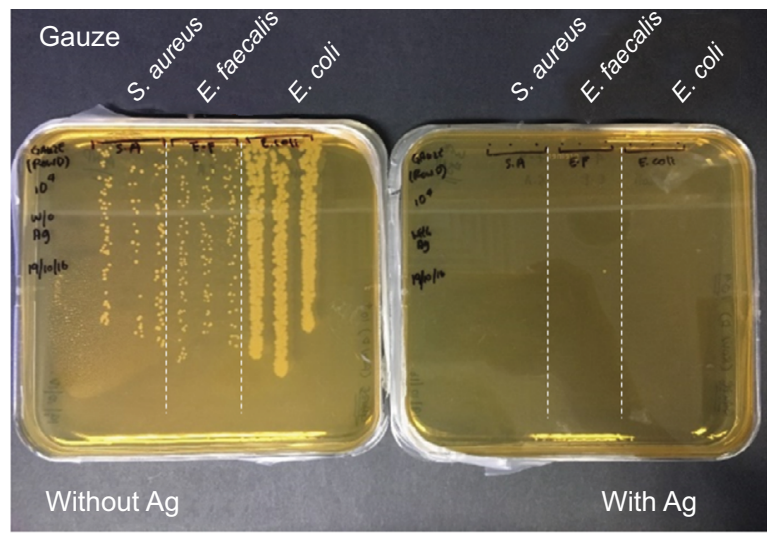

B

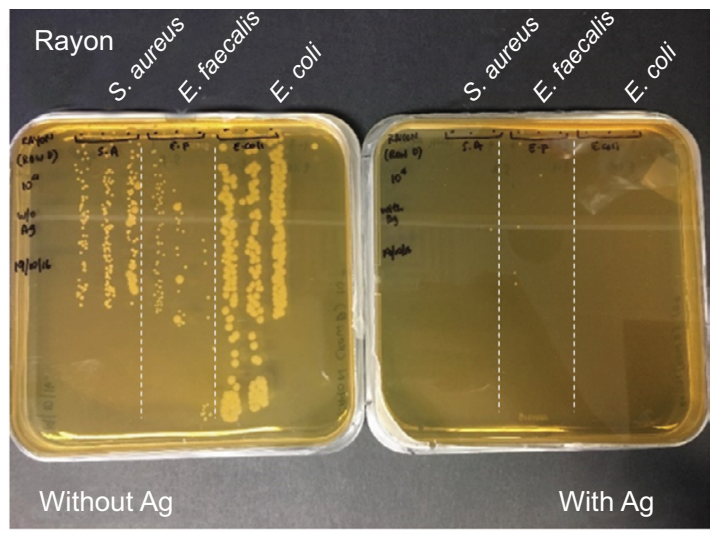

C

\begin{tabular}{|c|c|c|c|c|}
\hline \multicolumn{5}{|c|}{ Bacteria (log [colony forming unit/ $\left.\mathrm{cm}^{2}\right]$ ) } \\
\hline \multirow[b]{2}{*}{ Bacteria } & \multicolumn{2}{|c|}{ Rayon } & \multicolumn{2}{|c|}{ Gauze } \\
\hline & Control & Silver & Control & Silver \\
\hline S. aureus & $7.78 \pm 0.15$ & $0.10 \pm 0.17$ & $7.62 \pm 0.20$ & 0 \\
\hline E. faecalis & $7.42 \pm 0.33$ & $0.20 \pm 0.34$ & $7.79 \pm 0.01$ & 0 \\
\hline E. coli & $7.85 \pm 0.04$ & 0 & $7.97 \pm 0.02$ & 0 \\
\hline
\end{tabular}

Figure 5 The drop culture of three different strains of bacteria (Staphylococcus aureus, Enterococcus faecalis and Escherichia coli) after exposure to the silver nanoparticlesmodified fabrics for an hour: (A) rayon and (B) gauze. (C) The tabulation of the number of colony forming units/ $\mathrm{cm}^{2}$ of three different strains of bacteria after exposure to the silver nanoparticles-modified fabrics.

OD of the three bacteria in the presence of rayon modified with different silver loading. With no silver, the control (dark blue line) experiment showed exponential growth of all three bacteria (over 10-fold increase compared to initial OD). While $S$. aureus showed a continuous steady increase in OD, the growth of E. faecalis and E. coli plateaued after 3 $\mathrm{h}$ in the absence of silver. At moderate-to-high silver loading $(\geq 0.25 \%[\mathrm{w} / \mathrm{v}]$ of silver nitrate and BPEI $25 \mathrm{~K}$ in precursor solution), the OD remained at the baseline even after $24 \mathrm{~h}$, indicating the absence of bacterial growth. However, at the 

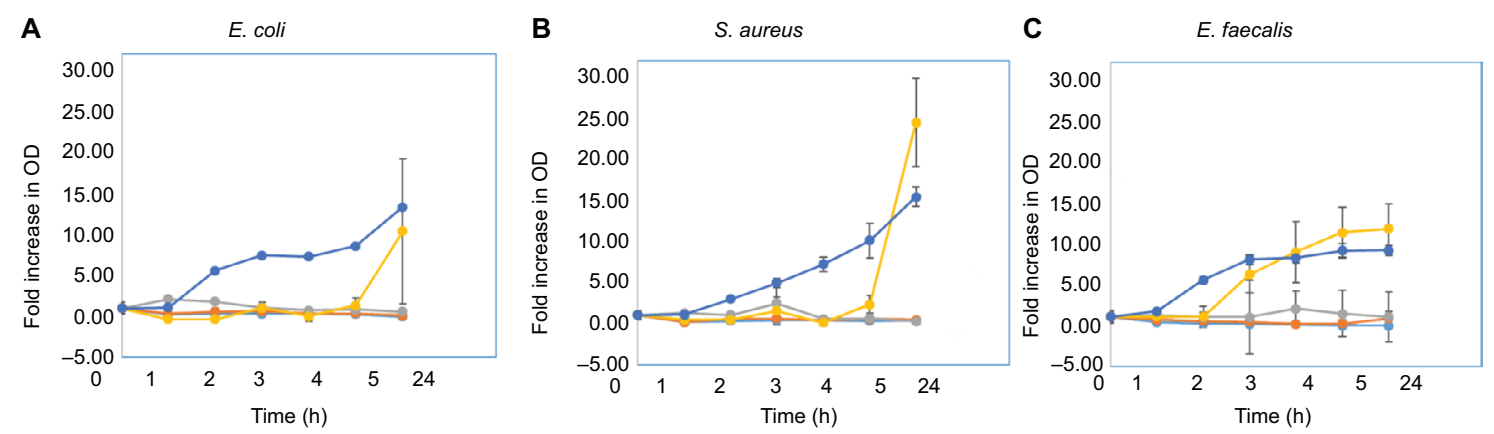

Figure 6 Optical density of (A) Escherichia coli, (B) Staphylococcus aureus and (C) Enterococcus faecalis exposed to rayon modified with a precursor solution containing I\% (w/v) (blue), $0.5 \%(w / v)($ red), $0.25 \%(w / v)$ (violet), $0.125 \%(w / v)$ (yellow) and $0 \%(w / v)$ (dark blue) silver nitrate and equal weight of BPEl 25K with a I-min simulated solar light irradiation.

Abbreviations: BPEI 25K, branched polyethylenimine of molecular weight 25,000; OD, optical density.

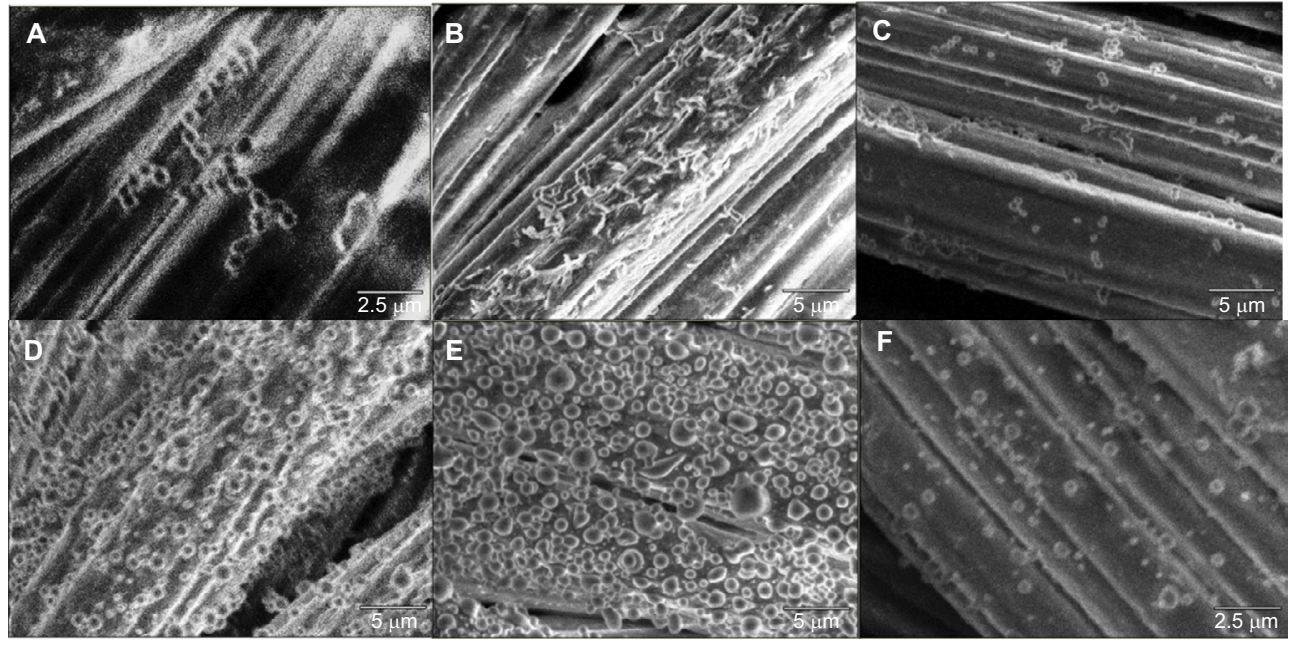

Figure 7 SEM images of unmodified rayon immersed in (A) Enterococcus faecalis, (B) Escherichia coli and (C) Staphylococcus aureus and silver nanoparticle-embedded rayon ( $1 \%[w / v]$ precursor solution) exposed to (D) E. faecalis, (E) E. coli and (F) S. aureus.

Abbreviation: SEM, scanning elecron microscopy.

lowest silver nanoparticle loading (made with $0.125 \%$ [w/v] precursor solution), bacterial growth was observed where the lag phase was different for each bacteria. S. aureus and E. coli transited from the lag to log phase in $5 \mathrm{~h}$ after exposure to silver nanoparticles. E. faecalis made the transition to $\log$ phase after $2 \mathrm{~h}$ of incubation. In this set of experiment, the differences in the OD response hinted that $E$. faecalis had higher resistance to silver in comparison to $S$. aureus and E. coli. At moderate-to-high silver dosage, the modified rayon was able to inhibit the growth of all three bacteria successfully.

Figure 7 depicts the SEM images of the functionalized rayon fabric exposed to the three bacteria. E. faecalis and $S$. aureus observed on unmodified rayon fibers showed the typical spherical morphology with bacteria attached to each other to form long chains or clusters, indicating bacterial division. In contrast, those found on the silver nanoparticlefunctionalized rayon fibers were individual cells where they appeared wrinkled, suggesting damaged cell membrane.
E. coli lost their rod-like morphology after exposure to silver treatment, indicating cell damage. The absence of clusters and chains of bacterial cells when exposed to functionalized fabric in Figure 7D-F suggests the inhibitory effect of silver on the growth and multiplication of bacteria.

From the antibacterial experiments, the silver nanoparticlemodified fabrics are capable of inhibiting growth of both Gram-positive and Gram-negative bacteria, as evidenced from the lack of growth of bacteria ( $S$. aureus, E. faecalis and E. coli) in Figures 5-7. The matrix on which the silver nanoparticles were embedded did not influence the antibacterial effectiveness. Both modified gauze and rayon were able to impede the growth of all the three species of bacteria.

\section{Conclusion}

In this article, a quick and convenient method of synthesizing metallic nanoparticles via light irradiation is detailed. Among the six different capping agents, BPEI was identified as the 
optimal as it has a good reducing capability which allowed smaller well-dispersed silver nanoparticles to form. The influence of light wavelength was found to be minimal as silver nanoparticles were formed under all the wavelengths tested (infrared, visible, UV and simulated solar light [xenon lamp]). The method was successfully translated to in situ synthesis of silver nanoparticles on five types of fabrics. This light-assisted "greener" nanoparticle synthesis provides an alternative to the laborious nanoparticle embedment process of pad-drycure conventionally employed for making nanoparticlefunctionalized fabrics. A high conversion rate of silver ions to silver nanoparticles ( $>90 \%$ ) helps to minimize wastage of substrates. Moreover, this method gave well-dispersed and strongly bound nanoparticles, mitigating the issue of aggregation which may render the nanoparticle less effective. The functional property of the silver nanoparticle-embedded fabrics as antibacterial surface was tested using three bacterial species. The growth of three different common species of bacteria ( $S$. aureus, E. faecalis and E. coli) was markedly inhibited when exposed to silver nanoparticle-modified rayon and cotton gauze. In short, our study showed the possibility of generating silver nanoparticle-functionalized fabrics without the use of caustic chemicals, solvents and excessive heating. The optimized method presents a major step towards realizing a scalable green chemistry for the industrial production of metallic nanoparticle-grafted fabrics.

\section{Acknowledgments}

The authors thank Miss Nur Anisah Binte Abdul Muthalib and Miss Dewi Amaleena Binte Sugen for their assistance in bacterial work. HST and RLF thank Miss Chua Yu En Cassandra, Miss Huang Tong Xuan and Miss Zara Teo Xiao Xuan for their active participation. HST would like to thank Miss Sim Joo Huang for her valuable help with scanning electron microscope and solar simulator.

\section{Disclosure}

HST and SG wish to acknowledge funding from MOE-TIF (MOE2015-TIF-1-G-037). The authors report no other conflicts of interest in this work.

\section{References}

1. Vance ME, Kuiken T, Vejerano EP, et al. Nanotechnology in the real world: redeveloping the nanomaterial consumer products inventory. Beilstein J Nanotechnol. 2015;6:1769-1780.

2. George S. Nanomaterial properties: implications for safe medical applications of nanotechnology. In: Kishen A, editor. Nanotechnology in Endodontics. Basel: Springer; 2015:45-69.
3. Ivask A, George S, Bondarenko O, Kahru A. Metal-containing nanoantimicrobials: differentiating the impact of solubilized metals and particles. In: Cioffi N, Rai M, editors. Nano-Antimicrobials. Berlin: Springer; 2011:253-290.

4. Eranka Illangakoon U, Mahalingam S, Wang K, et al. Gyrospun antimicrobial nanoparticle loaded fibrous polymeric filters. Mater Sci Eng C Mater Biol Appl. 2017;74:315-324.

5. Nowack B, Krug HF, Height M. 120 years of nanosilver history: implications for policy makers. Environ Sci Technol. 2011;45(4):1177-1183.

6. Zhang L, Fairbanks M, Andrew TL. Rugged textile electrodes for wearable devices obtained by vapor coating off-the-shelf, plain-woven fabrics. Adv Funct Mater. 2017;27(24):1700415.

7. Lee PC, Meisel D. Adsorption and surface-enhanced Raman of dyes on silver and gold sols. J Phys Chem. 1982;86(17):3391-3395.

8. Turkevich J, Stevenson PC, Hillier J. A study of the nucleation and growth processes in the synthesis of colloidal gold. Discuss Faraday Soc. 1951;11:55.

9. Mafuné F, Kohno J-Y, Takeda Y, Kondow T, Sawabe H. Formation and size control of silver nanoparticles by laser ablation in aqueous solution. J Phys Chem B. 2000;104(39):9111-9117.

10. Tsuji T, Thang DH, Okazaki Y, Nakanishi M, Tsuboi Y, Tsuji M. Preparation of silver nanoparticles by laser ablation in polyvinylpyrrolidone solutions. Appl Surf Sci. 2008;254(16):5224-5230.

11. George $\mathrm{S}$, Gardner $\mathrm{H}$, inventors. A method for producing polyethyleneimine (PEI) capped silver nanoparticles. Singapore Government patent 10201401114Q. 2015 Oct 29.

12. Dastjerdi R, Montazer M, Shahsavan S. A new method to stabilize nanoparticles on textile surfaces. Colloids Surf Physicochem Eng Aspects. 2009;345(1-3):202-210.

13. Rajendra R, Balakumar C, Ahammed HAM, Jayakumar S, Vaideki K, Rajesh E. Use of zinc oxide nano particles for production of antimicrobial textiles. Int J Eng Sci Technol. 2010;2(1):202-208.

14. Park SY, Chung JW, Priestley RD, Kwak S-Y. Covalent assembly of metal nanoparticles on cellulose fabric and its antimicrobial activity. Cellulose. 2012;19(6):2141-2151.

15. Gupta P, Bajpai M, Bajpai SK. Investigation of antibacterial properties of silver nanoparticle-loaded poly (acrylamide-co-itaconic acid)-grafted cotton fabric. J Cotton Sci. 2008;12:280-286.

16. Bajpai SK, Bajpai M, Sharma L, Yallapu MM. Silver nanoparticles loaded thermosensitive cotton fabric for antibacterial application. $J$ Ind Text. 2014;44(1):58-69.

17. Meng M, He H, Xiao J, Zhao P, Xie J, Lu Z. Controllable in situ synthesis of silver nanoparticles on multilayered film-coated silk fibers for antibacterial application. J Colloid Interface Sci. 2016;461:369-375.

18. Mahalingam S, Ren GG, Edirisinghe MJ. Rheology and pressurised gyration of starch and starch-loaded poly(ethylene oxide). Carbohydr Polym. 2014;114:279-287.

19. Zhang S, Karaca BT, VanOosten SK, et al. Coupling infusion and gyration for the nanoscale assembly of functional polymer nanofibers integrated with genetically engineered proteins. Macromol Rapid Commun. 2015;36(14):1322-1328.

20. Hong X, Mahalingam S, Edirisinghe M. Simultaneous application of pressure-infusion-gyration to generate polymeric nanofibers. Macromol Mater Eng. 2017;302(6):1600564.

21. Xu Z, Mahalingam S, Basnett $P$, et al. Making nonwoven fibrous poly( $\varepsilon$-caprolactone) constructs for antimicrobial and tissue engineering applications by pressurized melt gyration. Macromol Mater Eng. 2016;301(8):922-934.

22. Mahalingam S, Edirisinghe M. Forming of polymer nanofibers by a pressurised gyration process. Macromol Rapid Commun. 2013;34(14):1134-1139.

23. George S, Gardner H, Seng EK, et al. Differential effect of solar light in increasing the toxicity of silver and titanium dioxide nanoparticles to a fish cell line and zebrafish embryos. Environ Sci Technol. 2014;48(11):6374-6382. 
24. George S, Lin S, Ji Z, et al. Surface defects on plate-shaped silver nanoparticles contribute to its hazard potential in a fish gill cell line and zebrafish embryos. ACS Nano. 2012;6(5):3745-3759.

25. Li H, Fang CH, Shi W, et al. Size and site dependent biological hazard potential of particulate matters collected from different heights at the vicinity of a building construction. Toxicol Lett. 2015;238(3): 20-29.

26. Shechter H, Rawalay SS. Oxidation of primary, secondary, and tertiary amines with neutral potassium permanganate. II. J Am Chem Soc. 1964;86(9):1706-1709.

27. Sakamoto M, Fujistuka M, Majima T. Light as a construction tool of metal nanoparticles: synthesis and mechanism. J Photochem Photobiol C. 2009;10(1):33-56.

28. Evanoff DD Jr, Chumanov G. Size-controlled synthesis of nanoparticles. 2. Measurement of extinction, scattering, and absorption cross sections. J Phys Chem B. 2004;108(37):13957-13962.

29. Dobias B, Qiu X, Rybinski WV. Solid-Liquid Dispersions. Vol 81. New York: Mercel Dekker Inc.; 1999.
30. Zhang H, Xia T, Meng H, et al. Differential expression of syndecan-1 mediates cationic nanoparticle toxicity in undifferentiated versus differentiated normal human bronchial epithelial cells. ACS Nano. 2011;5(4):2756-2769.

31. El Badawy AM, Silva RG, Morris B, Scheckel KG, Suidan MT, Tolaymat TM. Surface charge-dependent toxicity of silver nanoparticles. Environ Sci Technol. 2011;45(1):283-287.

32. Hajipour MJ, Fromm KM, Ashkarran AA, et al. Antibacterial properties of nanoparticles. Trends Biotechnol. 2012;30(10):499-511.

33. Li WR, Xie XB, Shi QS, Duan SS, Ouyang YS, Chen YB. Antibacterial effect of silver nanoparticles on Staphylococcus aureus. Biometals. 2011;24(1):135-141.

34. Holt KB, Bard AJ. Interaction of silver(I) ions with the respiratory chain of Escherichia coli: an electrochemical and scanning electrochemical microscopy study of the antimicrobial mechanism of micromolar Ag+. Biochemistry. 2005;44(39):13214-13223.

35. Feng QL, Wu J, Chen GQ, Cui FZ, Kim TN, Kim JO. A mechanistic study of the antibacterial effect of silver ions on Escherichia coli and Staphylococcus aureus. J Biomed Mater Res. 2000;52(4):662-668. 


\section{Supplementary materials}

\section{Information on simulated solar light}

The xenon lamp (XES Series Class AAA solar simulator, XES-1600SE-200S; IVT Solar, Singapore, Singapore) used in our studies conforms to ASTM 927-91 Class A and IEC 904-9 Class A irradiance uniformity requirements. With the fitted optical filters, the light spectrum was matched to achieve air mass 1.5 consistent with ASTMG173-03 and IEC 60904-3:2008. Figure S1 displays the wavelength spectra comparing the xenon lamp against the standard of ASTMG173 provided by the supplier. The light energy was ensured to be at $1 \mathrm{Sun}\left(1000 \mathrm{~W} \cdot \mathrm{m}^{-2}\right)$ via calibration with a monocrystalline silicon cell (certified by Fraunhofer ISE).

\section{Gold nanoparticle-modified textiles}

Instead of adding silver nitrate as detailed in the protocol for generating silver nanoparticle, gold(III) chloride was used in this experiment. Upon mixing gold(III) chloride with branched polyethylenimine of molecular weight 10,000

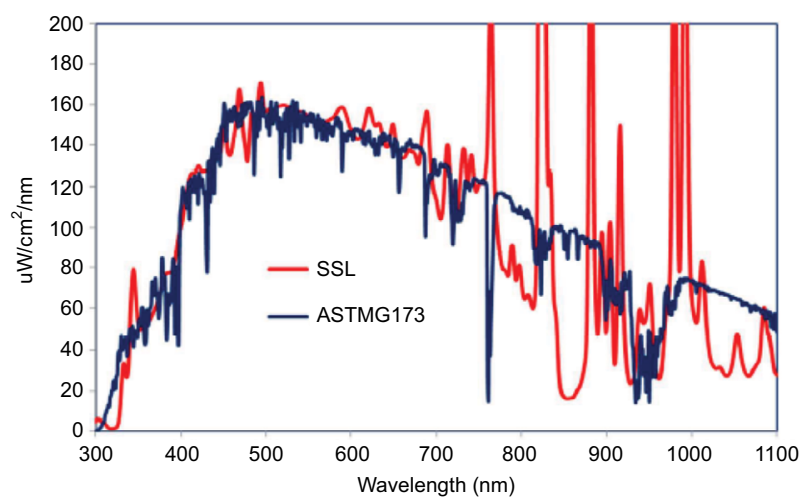

Figure SI The wavelength spectra of the xenon lamp (simulated solar light) and the standard of ASTMGI73 provided by the supplier.

Abbreviation: SSL, simulated solar light.

A

\begin{tabular}{|c|c|c|c|c|}
\hline $\begin{array}{c}\text { Irradiation } \\
\text { source }\end{array}$ & Power & Time & Wavelength & $\begin{array}{c}\text { Hydrodynamic } \\
\text { diameter (nm) of } \\
\text { Ag NP }\end{array}$ \\
\hline Xenon lamp & $1000 \mathrm{~W}$ & $1 \mathrm{~min}$ & $400-1000 \mathrm{~nm}$ & $65.1 \pm 0.3$ \\
\hline Infrared & $150 \mathrm{~W}$ & $6 \mathrm{~min} 20 \mathrm{~s}$ & $\begin{array}{c}\text { max emission at } \\
100 \mathrm{~nm}-1 \mathrm{~mm},\end{array}$ & $71.0 \pm 0.8$ \\
\hline UV & $30 \mathrm{~W}$ & $33 \mathrm{~min} 20 \mathrm{~s}$ & $10-400 \mathrm{~nm}$ & $82.1 \pm 0.5$ \\
\hline
\end{tabular}

(BPEI 10K) in the dark, a color change from yellow $\left(\mathrm{Au}^{3+}\right)$ to red (signature color of $\mathrm{Au}$ nanoparticles) was observed within minutes. ${ }^{1-3}$ The gold nanoparticles were also successfully embedded onto the five fabrics by adding the freshly made nanoparticle suspension onto the textile. Moving down the rows, the red colorization decreased in intensity as the gold concentration decreased. At the last row, only $1 \%(\mathrm{w} / \mathrm{v})$ gold(III) chloride was added. Despite with 1-min irradiation from solar simulator, no color change was observed, and thus, no gold nanoparticle was formed in the absence of BPEI $10 \mathrm{~K}$. Therefore, the presence of BPEI $10 \mathrm{~K}$ is crucial for the formation of gold nanoparticles.

\section{Scale-up strategy}

To adapt the synthesis method onto a production line, we envision that the unmodified fabrics can be loaded onto a conveyor belt. The fabrics then undergoes a precursor spray

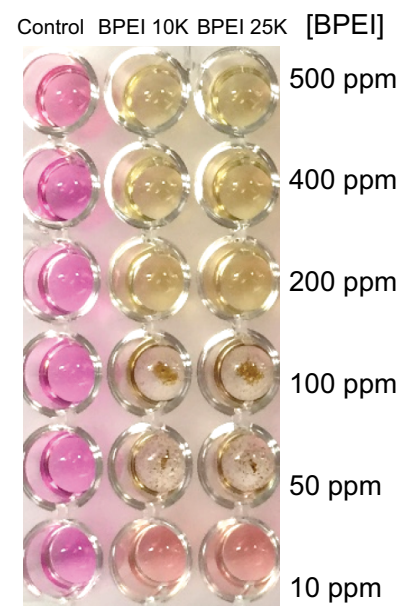

Figure S3 Incremental concentration of BPEI IOK and BPEI 25K added to 100 PPm of potassium permanganate produced concentration-dependent decrease in the purple color. Notably, there was formation of dark precipitates at 50 and $100 \mathrm{ppm}$ contributing to a spike in the absorbance at $520 \mathrm{~nm}$.

B

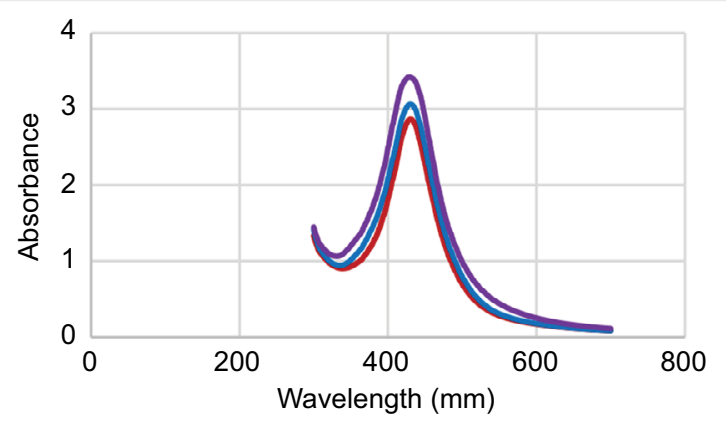

Figure S2 (A) The various light sources and their characteristics, and the corresponding hydrodynamic diameter of the silver nanoparticles formed using a precursor solution of $1 \%(\mathrm{w} / \mathrm{v})$ silver nitrate and I\% (w/v) BPEI 25K. (B) The UV-vis spectrum of the synthesized silver nanoparticles obtained using various irradiation sources. Blue: xenon lamp; purple: UV; red: infrared.

Abbreviations: BPEI 25K, branched polyethylenimine of molecular weight 25,000; NP, nanoparticle. 


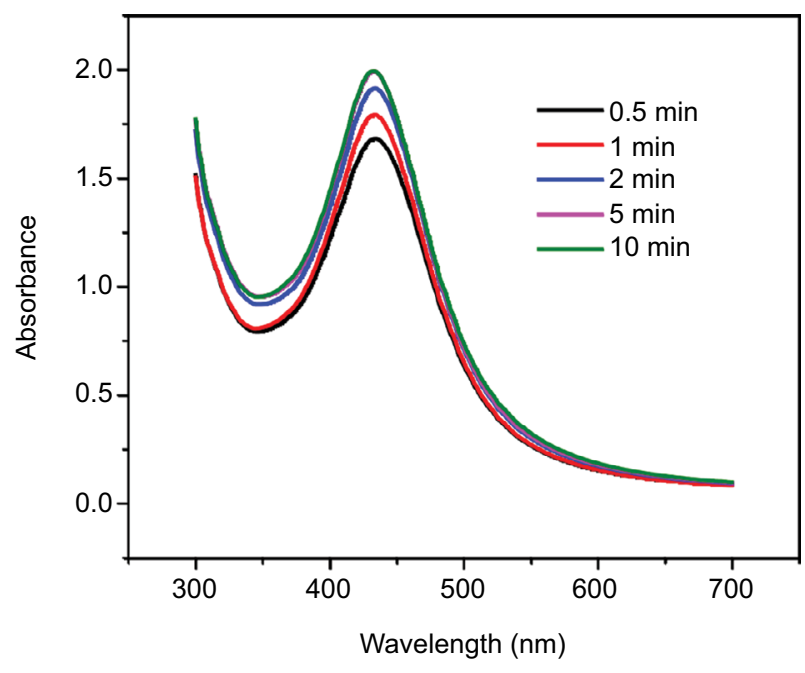

Figure S4 The UV-vis spectrum of the synthesized silver nanoparticles formed using a precursor solution of I\% (w/v) silver nitrate and I\% (w/v) BPEI $25 \mathrm{~K}$ with natural sunlight at various irradiation periods.

Abbreviation: BPEI 25K, branched polyethylenimine of molecular weight 25,000.

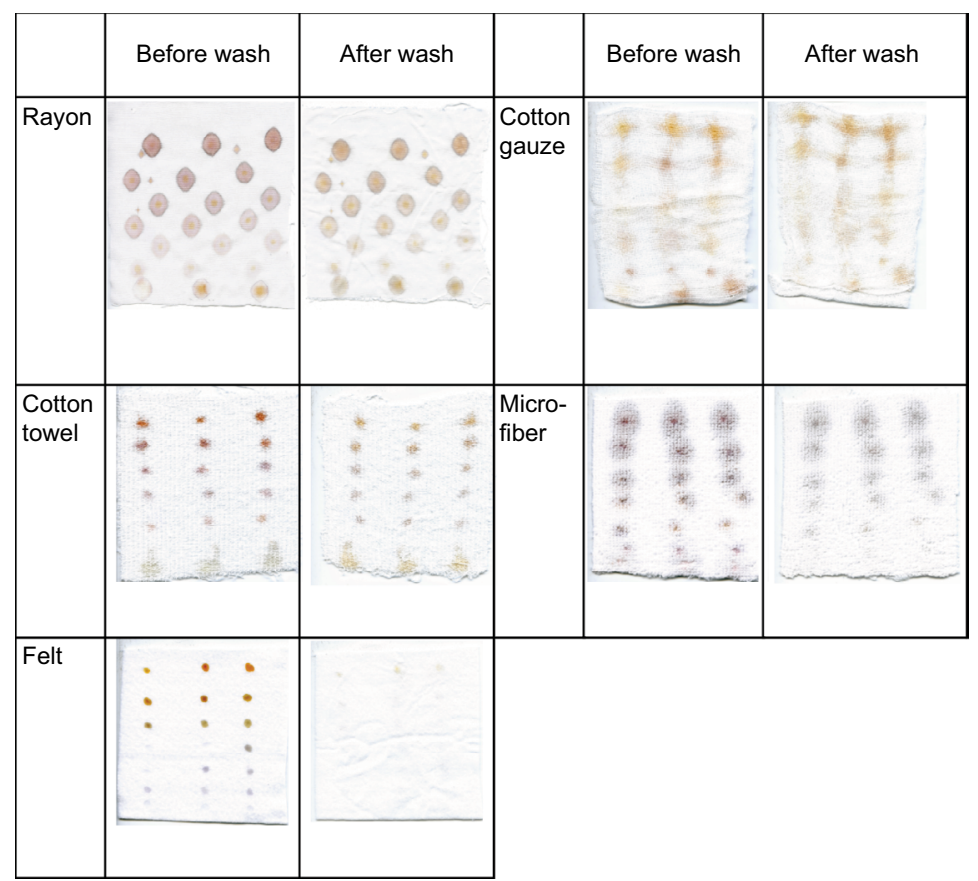

Figure S5 In situ synthesis of silver nanoparticles on various fabrics via simulated solar light irradiation for I min with a decreasing amount of silver nitrate and BPEI IOK $(0.03-1 \%, w / v)$ down the rows. The bottom row represents $1 \%(w / v)$ silver nitrate with no capping agent.

Abbreviation: BPEI IOK, branched polyethylenimine of molecular weight 10,000.
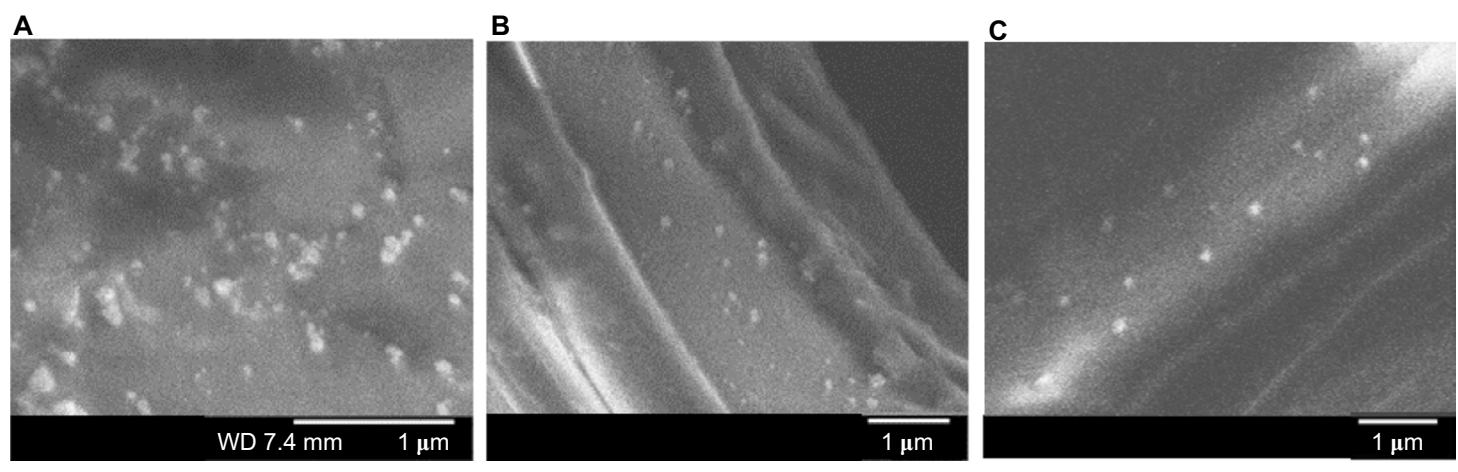

Figure S6 SEM images of fabrics modified with BPEI 25K-capped silver nanoparticles: (A) felt, (B) microfiber and (C) cotton towel. Abbreviations: SEM, scanning elecron microscopy; BPEI 25K, branched polyethylenimine of molecular weight 25,000. 


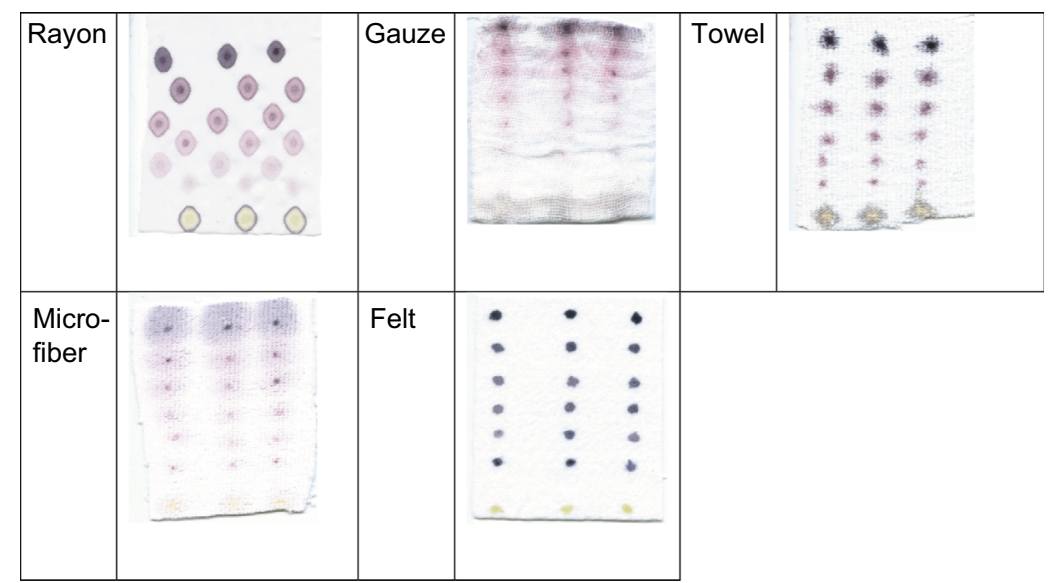

Figure S7 In situ synthesis of gold nanoparticles on various fabrics via simulated solar light irradiation for I min with a decreasing amount of gold chloride and BPEI IOK $(0.03-1 \%, w / v)$ down the rows. The bottom row represents $1 \%(w / v)$ gold chloride with no capping agent.

Abbreviation: BPEI IOK, branched polyethylenimine of molecular weight 10,000.

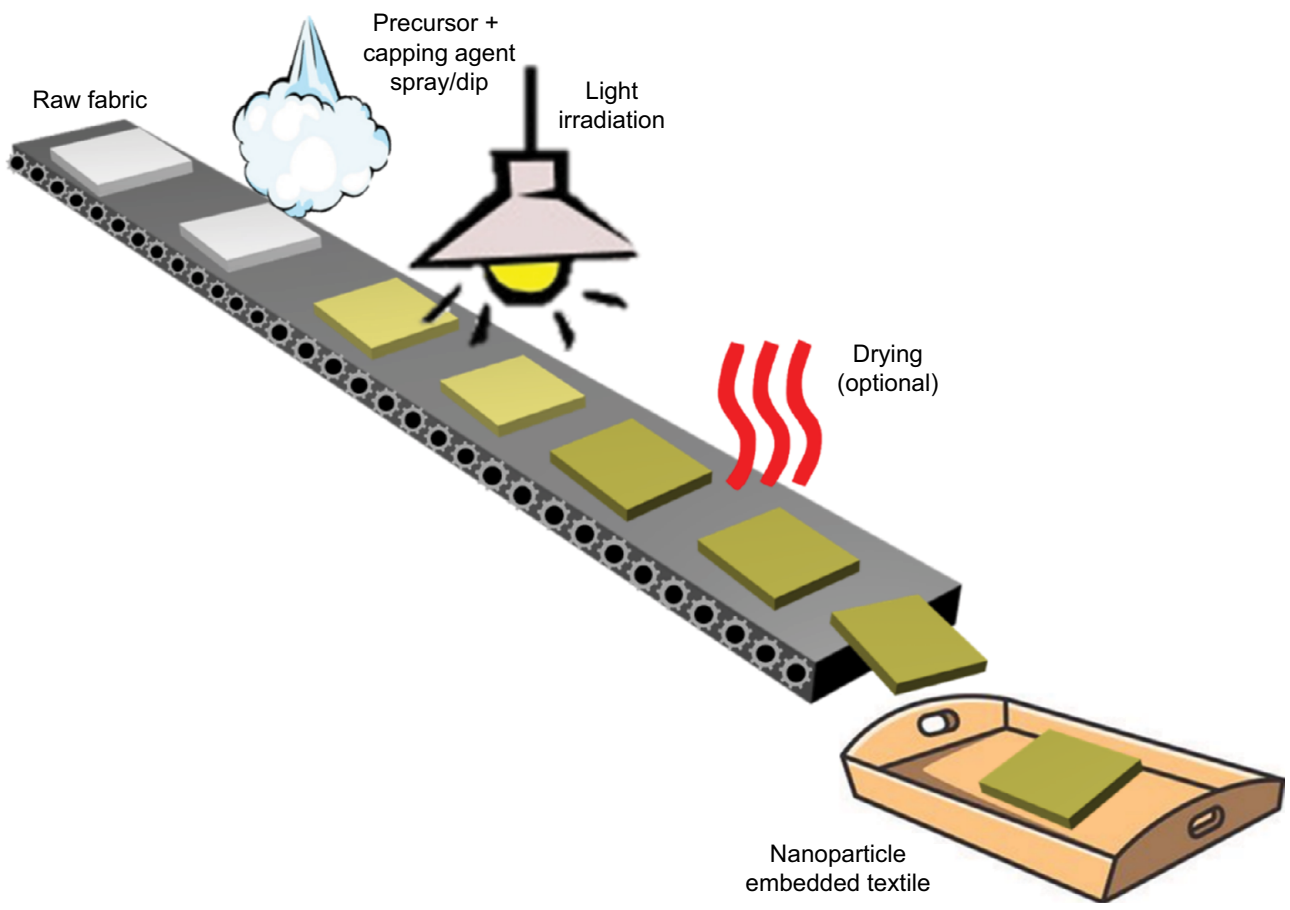

Figure $\mathbf{8} 8$ The possible industrial upscaling of the in situ synthesis of silver nanoparticles on fabrics on a conveyor belt.

containing silver nitrate and BPEI before being delivered under light irradiation for the photosensitive reaction to take place. A quick drying step would ensure the textiles are dried and ready for usage.

\section{Potassium permanganate study}

The sharp increase in absorbance observed in the well of $100 \mathrm{ppm}$ of BPEI and $100 \mathrm{ppm}$ potassium permanganate was probably due to the formation of large amount of black manganese oxide which attributed to additional scattering of light. As BPEI was added to potassium permanganate, black manganese oxide solid was formed as evident by the increasing amount of sediments at the bottom of the well from
10 to $100 \mathrm{ppm}$ of BPEI in Figure S6. The sediments scattered light leading to an increase in absorbance. When greater concentrations of BPEI were added, colorless manganese(II) ions were formed instead of the black solid, reducing the scattering effect on absorbance.

\section{References}

1. Evanoff Jr DD, Chumanov G. Size-controlled synthesis of nanoparticles. 2. Measurement of extinction, scattering, and absorption cross sections. J Phys Chem B. 2004;108(37):13957-13962.

2. Evanoff Jr DD, Chumanov G. Synthesis and optical properties of silver nanoparticles and arrays. ChemPhysChem. 2005;6(7):1221-1231.

3. Haiss W, Thanh NTK, Aveyard J, Fernig DG. Determination of size and concentration of gold nanoparticles from UV-vis spectra. Anal Chem. 2007;79(11):4215-4221. 
Nanotechnology, Science and Applications is an international, peer-reviewed, open access journal that focuses on the science of nanotechnology in a wide range of industrial and academic applications. It is characterized by the rapid reporting across all sectors, including engineering, optics, bio-medicine, cosmetics, textiles, resource sustainability and science. Applied research into nano-materials, particles, nano-structures and fabrication, diagnostics and analytics, drug delivery and toxicology constitute the primary direction of the journal. The manuscript management system is completely online and includes a very quick and fair peer-review system, which is all easy to use. Visit http://www.dovepress.com testimonials.php to read real quotes from published authors. 